\title{
As atividades de grupo na perspectiva dos sujeitos em uma Clínica da Família
}

\section{| ${ }^{1}$ Lorraine Santiago Rego, ${ }^{2}$ Gustavo de Oliveira Figueiredo, ${ }^{3}$ Valeria Ferreira Romano, ${ }^{4}$ Mirian Ribeiro Baião I}

Resumo: Este estudo visa analisar os sentidos que os sujeitos conferem às atividades de grupos realizadas em uma Clínica da Família no Rio de Janeiro. Os dados foram coletados por meio de entrevistas semiestruturadas, aplicadas aos participantes, e observação sistemática dos encontros de três grupos distintos. As informaçóes foram processadas pela adaptação da análise de conteúdo temática, com apoio da perspectiva interpretativista. Foram identificadas três categorias analíticas no material empírico, a saber: "dimensão biológica", "dimensão psicoafetiva" e "dimensão educativa”. As trocas interpessoais se processaram principalmente pela reflexão proveniente da experiência de vida dos sujeitos, o que possibilitou aproximação diferenciada sobre as necessidades de cuidado dos usuários a partir do acolhimento proporcionado pelo coletivo e dos vínculos construídos. Os resultados demonstram que as abordagens de grupo podem contribuir com a transformação do modelo hegemônico biomédico das práticas de saúde.

> Palavras-chave: Atenção Primária à Saúde; Promoção da Saúde; Educação em Saúde; Medicina de Família e Comunidade.

\author{
1 Programa de Mestrado \\ Profissional em Atenção Primária \\ à Saúde, Universidade Federal do \\ Rio de Janeiro. Rio de Janeiro-RJ, \\ Brasil (lorrainesanr@gmail.com). \\ ORCID: 0000-0001-8602-3112. \\ 2 Instituto Nutes de Educação em \\ Ciências e Saúde, Universidade \\ Federal do Rio de Janeiro. Rio de \\ Janeiro-RJ, Brasil (gfigueiredo. \\ ufrj@gmail.com). \\ ORCID: 0000-0003-2724-8826. \\ ${ }^{3}$ Medicina de Saúde e \\ Comunidade, Universidade \\ Federal do Rio de Janeiro. \\ Rio de Janeiro-RJ, Brasil \\ (valeriaromano34@gmail.com). \\ ORCID: 0000-0002-6646-2879. \\ ${ }^{4}$ Instituto de Nutrição Josué de \\ Castro, Universidade Federal do \\ Rio de Janeiro. Rio de Janeiro-RJ, \\ Brasil (mirianbaiao@uol.com.br) \\ ORCID: 0000-0002-2002-9666.
}

Recebido em: 14/02/2019 Revisado em: 15/05/2019 Aprovado em: 06/06/2019 


\section{Introdução}

No âmbito da Saúde Coletiva, a Promoção da Saúde (PS) tem sido fortalecida, sobretudo diante do fracasso do tradicional modelo biomédico em lidar com o complexo e multidimensional fenômeno do adoecimento humano. Nas últimas quatro décadas, foram realizadas importantes conferências internacionais e publicados documentos sobre o tema, motivados pela crescente insatisfação com a acentuada medicalizaçáo da sociedade, a falência do modelo de medicina curativa, de alto custo, e a baixa eficácia do sistema público de saúde (BUSS, 2003).

As publicaçôes que emergiram, como o Informe Lalonde (1974), Declaração de Alma-Ata (1978) e Carta de Ottawa (1986), tinham em comum o discurso da multideterminação do processo saúde-doença e apontavam a necessidade de desenvolver açôes efetivas com vistas à saúde das populaçôes, por meio do fortalecimento da autonomia dos sujeitos e da maior participação e controle social. Como afirma Buss (2003), ao mesmo tempo que estimularam a participação popular, tais concepçóes também pautaram a agenda dos setores governamentais, pressionando os países a implementarem políticas públicas saudáveis.

Como consequência desses movimentos, o Brasil adotou, em 1988, no texto da Constituição Federal, uma concepção ampliada de saúde, entendendo-a como resultado das condições de vida, alimentação, trabalho, moradia, educação, transporte, lazer, etc., que também orientou o desenvolvimento do Sistema Único de Saúde (SUS). Entretanto, foi somente em março de 2006 que o país formulou e implementou a Política Nacional de Promoção da Saúde (PNPS) (BRASIL, 2015).

Desde entáo, aconteceram diversos outros movimentos internacionais, que aprimoraram os planos para o enfrentamento dos desafios na saúde, como por exemplo, a declaração de Adelaide (2010) sobre o tratamento de doenças crônicas não transmissíveis (DCNT), e a Conferência de Helsinque (2013), a qual abordou a inclusão da saúde como eixo intersetorial de todas as políticas. Além disso, em âmbito nacional, os governos buscaram responder diversas demandas do campo da Saúde Coletiva, por meio de um conjunto de iniciativas, como a Política Nacional de Atenção Básica (PNAB, 2017), a Política Nacional de Humanização (PNH/ Humaniza-SUS, 2010), a Política Nacional de Educação Popular em Saúde no Sistema Único de Saúde (PNEP-SUS, 2013) e a Política Nacional de Promoção da Saúde (PNPS) (BRASIL, 2015). 
Cabe ressaltar que a formulação, pelo Estado, de políticas públicas, a exemplo das políticas de saúde, traz a reflexão sobre o que se faz em nome do Estado e de sua racionalidade. Essa formulação não tem uma concepção linear, ou seja, se constitui segundo diferentes percepçôes de mundo, já que estão repletas de embates e conflitos de interesses e expressam acordos dinâmicos e momentâneos, dentro de um contexto histórico de um Estado liberal (MATTOS; BAPTISTA, 2015; MALTA et al., 2016).

Nesse sentido, com relação à PNPS, pode-se dizer que a Promoção da Saúde ainda está em construção, tanto no campo das ideias quanto da prática. De acordo com Silva e Baptista (2015), os documentos que tratam da PNPS apresentam "convergências e divergências" inerentes aos contextos políticos, sociais e disputas próprias de cada tempo. Para os autores, o documento de 2006 aproxima a promoção à Vigilância em Saúde e à prevenção, por meio da mudança dos estilos de vida e redução de fatores de risco, ainda que fundamentado no conceito ampliado de saúde. O texto mais recente da PNPS mantém o foco em torno da redução da vulnerabilidade, dos riscos à saúde, visando equidade, melhoria das condiçōes e qualidade de vida. Porém, se diferencia do anterior ao apresentar um conjunto de valores essenciais para a implementação da política, com destaque para: solidariedade, felicidade, ética e respeito à diversidade.

O debate sobre promoção ainda exige muita reflexão sobre os sentidos que se desejam alcançar ao materializar a política em açóes concretas no campo da saúde. Alguns sentidos associam promoção à realização de açóes de educação sanitária e grupos terapêuticos, com vistas à prevenção e controle das doenças e ênfase em hábitos saudáveis. Outro sentido remete à compreensão sobre os determinantes sociais da saúde e doença, associando promoção, autonomia e emancipação dos sujeitos ao cuidado por meio de políticas de natureza intersetorial (SILVA; BAPTISTA, 2014).

As diferentes concepçóes teóricas acabam por fragilizar as práticas de promoção que, frequentemente pautadas na pedagogia tradicional, reforçam mudanças nos modos de vida segundo construtos culpabilizantes ou discursos focados exclusivamente em um olhar biológico e reducionista sobre a vida e a autonomia dos sujeitos, gerando normatização e normalização dos corpos (FOUCAULT, 1980). Assim, no âmbito das práticas de produção da saúde, a superação de uma educação técnica, que engessa e reproduz concepçôes hegemônicas, descontextualizadas da realidade dos sujeitos e dos sentidos que atribuem à saúde, para uma educação emancipatória, que busca a autonomia e transformação social, tem se mostrado um grande desafio (LOPES; TOCANTINS, 2012). 
Informado pela racionalidade biomédica, o campo da saúde - ou seja, saberes, técnicas, instituiçôes, tecnologias e profissôes - agrega uma responsabilidade inegável na disponibilidade para a medicalização da vida (NASCIMENTO; ROMANO; MOSEGUI, 2017), constituindo uma narrativa de poder sobre a vida e a existência das pessoas (CAMARGO JR., 2005), e é com esse olhar que este estudo foi concebido.

Consoante as proposiçóes prático-conceituais da Promoção da Saúde, é essencial conhecer o potencial que as experiências nesse campo portam, particularmente nos espaços moleculares do trabalho vivo. A Atenção Primária em Saúde (APS) é estratégica para esse fim, por estar inserida no território onde as pessoas moram, trabalham, estudam e vivem, tendo entendimento da realidade local. Este artigo visa contribuir nessa direçâo, ao analisar os sentidos que os sujeitos conferem às atividades coletivas, materializadas na forma de grupos educativos (terapêuticos), com um seguimento longitudinal, realizadas em uma Clínica da Família (CF), no Rio de Janeiro. Para o estudo, selecionamos entrevistar os participantes e observar o funcionamento de três grupos distintos.

\section{Método}

Pesquisa do tipo descritivo-exploratória (GIL, 2008), construída por meio da abordagem qualitativa, apoiada na perspectiva interpretativista. Para os interpretativistas, o significado de um fenômeno pode ser descoberto e compreendido pelo intérprete por meio de uma visão objetivista. Implica um processo intelectual, balizado pelo respeito e fidelidade à experiência de vida dos sujeitos, os quais possuem uma autocompreensão de suas açóes. Cabe ao pesquisador/intérprete reconstruir as autocompreensóes dos atores, entendendo o contexto no qual suas açóes fazem ou adquirem sentido para compreender a ação específica. Assim, há que se reconhecer e compreender a relação entre o todo e parte, postura que se buscou desenvolver, neste estudo, durante todo o processo de construção e análise de dados (SCHWANDT, 2006).

O estudo foi desenvolvido entre 2016 e 2017, em uma Clínica da Família situada no complexo do Morro dos Macacos, no Rio de Janeiro - território caracterizado por aglomeraçôes de casas, construídas sem planejamento habitacional; presença de grande quantidade de lixo e esgoto a céu aberto em diversas partes. Algumas casas precárias, úmidas, com pouca ventilação e risco de desabamento. A violência 
constante na comunidade, com a presença do tráfico de drogas. Ao andar pelas ruas, becos e vielas, não era difícil encontrar membros do tráfico fortemente armados, e a venda de drogas também ocorria de forma desvelada.

Em junho de 2016, a unidade possuía cerca de 10.700 pessoas e 3.900 famílias cadastradas, cuja responsabilidade era dividida entre quatro equipes, cada uma delas composta por: um médico, uma enfermeira, um técnico de enfermagem, seis agentes comunitários de saúde. Havia ainda um dentista e um técnico de saúde bucal para cada duas equipes. A unidade contava também com profissionais do Núcleo de Apoio à Saúde da Família (NASF), composto por um psiquiatra, uma assistente social, uma psicóloga, uma educadora física, uma fisioterapeuta e um médico especialista em tratamento da dor.

A CF promovia, à época do estudo, seis grupos educativos: Bem-estar, Atividade física funcional, Artesanato, Saúde da mulher, Planejamento familiar e grupo de Gestantes. Cabe ressaltar que somente os três primeiros grupos foram escolhidos para a pesquisa, já que os demais apresentavam alta rotatividade dos usuários, o que poderia comprometer o caráter longitudinal do cuidado em saúde bem como a perspectiva de inclusão, no estudo, de participantes mais assíduos. Neste sentido, foram utilizados os seguintes critérios de inclusão dos sujeitos no estudo: usuário cadastrado na CF, com idade acima de 18 anos, participaçáo igual ou superior a cinco vezes em qualquer um dos três grupos.Para o acompanhamento dos grupos foi aplicada a técnica de observação sistemática, a fim de se obter maior compreensão sobre as dinâmicas grupais, os sujeitos, as relações interpessoais e as expressôes não verbais (MARCONI; LAKATOS, 2003). Ao longo da pesquisa, foi possível acompanhar três encontros do grupo de Atividade funcional e três encontros do Artesanato. Entretanto, não foi possível acompanhar mais que um encontro do Bem-estar, uma vez que este foi bruscamente interrompido, devido à necessidade de mudança da agenda do profissional que coordenava o grupo, para atendimento às demandas burocráticas do serviço, fato que demonstra a fragilidade das atividades educativas na unidade.

Além das observações diretas nos grupos, selecionamos alguns participantes para responderem à entrevista semiestruturada. Todas as entrevistas foram realizadas no período de dezembro de 2016 a abril de 2017, na própria unidade de saúde, em uma área reservada e em horário mais conveniente para os entrevistados, sendo gravadas e transcritas por meio do registro autêntico dos enunciados. 
A quantidade de entrevistas foi considerada satisfatória quando os dados do estudo foram se tornando repetitivos, considerando as múltiplas dimensóes do objeto (MINAYO, 2014). A autorização para os sujeitos participarem da pesquisa foi expressa por meio de Termo de Consentimento Livre e Esclarecido, recomendado para pesquisas com seres humanos pela Resolução No 466/2012, do Conselho Nacional de Saúde (BRASIL, 2012).

A pesquisa foi aprovada pelo Comitê de Ética e Pesquisa da instituição UFRJ Escola de Enfermagem Anna Nery/ EEAN - Hospital Escola São Francisco de Assis em 25/10/2016, parecer no 1790884, e pela instituição coparticipante da Secretaria Municipal de Saúde do Rio de Janeiro - SMS/RJ em 09.11.2016, parecer no 1813138.

Após reflexão sobre as observaçôes descritas em um diário de campo, bem como a escuta e leitura das transcriçóes das entrevistas semiestruturadas, o material foi tratado em três etapas: exploração, organização e interpretação, com vistas à Análise de Conteúdo (AC), adaptada da modalidade temática, proposta por Bardin (2008).

Buscou-se apreender a participação nos grupos por meio de três categorias de análise, cujos sentidos nucleadores contribuíram para definição das mesmas, como: "a dimensão biológica", "a dimensão psicoafetiva" e "a dimensão educativa”. A seguir, apresentaremos os resultados da pesquisa organizados nessas três dimensôes.

\section{Resultados}

Os grupos escolhidos para o estudo eram intitulados e desenvolvidos pelos coordenadores, e conforme a denominação (Bem-estar, Atividade física funcional e Artesanato), revelavam intençôes mais condizentes com o modelo preventivista, por meio do estímulo à prática de atividade física adequada, do desenvolvimento de habilidades manuais, ou da criação de oportunidades de disseminação de conhecimentos sobre "estilos de vida saudáveis", visando alcançar melhores padrôes de saúde. Embora a abordagem focasse mais nos conteúdos do que nos sujeitos, em alguns momentos os grupos podiam mudar o rumo, quase sempre por demandas que emergiam dos participantes, conforme será analisado adiante, por meio das dimensôes apreendidas no estudo.

Foram entrevistados 21 usuários da unidade, sendo sete adultos, com idade entre 27 e 56 anos, e 14 idosos, entre 62 e 77 anos. Dezesseis eram do sexo feminino e cinco do sexo masculino. Onze frequentavam o grupo Bem-estar; 15 participavam 
do grupo de Atividade física funcional; e seis participavam do grupo de Artesanato. Alguns deles participavam de mais de um grupo. O perfil dos participantes entrevistados pode ser assim resumido: sexo feminino, com faixa etária acima de 50 anos, casados, renda familiar menor que três salários mínimos, baixa escolaridade e sem ocupação laboral.

\section{Dimensão educativa}

Esta dimensão foi pautada na perspectiva dos participantes de buscarem aumentar o conhecimento em saúde e/ou adquirirem novos hábitos de vida ou melhorar habilidades e capacidades pessoais. Foi possível perceber que havia certa satisfação por estarem em um espaço em que algo era ensinado. Independentemente da expectativa, se aquelas orientaçôes tinham ou não efeito ou significado para suas vidas, o fato é que as pessoas demostraram algum agrado por estarem aprendendo.

[...] aquilo que a gente aprendeu, a gente pode praticar em casa. Às vezes, eu levanto de manhã, eu mesmo faço uns exercícios, que eu faço no grupo (de atividade física), faço em casa. (Sujeito 11, mulher 62, anos, aposentada, viúva).

Aprendi mais aqui nas palestras. Porque aqui tinha mais as explicaçôes do que podia fazer, do que não podia fazer. (Sujeito 8, mulher, 72 anos, aposentada, viúva).

[...] é muito bom ter uma pessoa que entende, igual médicos, pra gente que é analfabeto, aprender as coisas. (Sujeito 7, mulher, 65 anos, aposentada, viúva).

A satisfação por estarem aprendendo coisas novas esteve presente, de forma mais enfática, no grupo Bem-estar. Interessante observar que, em diversos momentos, os participantes se referiam ao mesmo com o nome de "palestra". Essa abordagem carrega as raízes culturais das práticas educativas, que se avigoraram ao longo do século XX, com a culminância do paradigma cartesiano e da medicina científica, segundo os quais a visão biologicista das doenças tornava as açôes de educação uma tentativa de modificar comportamentos inadequados. Uma das estratégias mais utilizadas ainda se configura nas palestras e, habitualmente, se limita à transmissão de conhecimentos pelos profissionais, enquanto aos partícipes cabe apenas ouvir e obedecer às recomendações (ALVES; AERTS, 2011).

Os participantes se colocavam em um papel de ouvintes, recebendo os conhecimentos de forma passiva, em uma relação de dominação do educador sobre o educando (FREIRE, 1987). Não houve críticas a esse modelo, ao contrário, estava embutida uma hipervalorização do saber do profissional, que direcionava a 
dinâmica grupal por meio de estratégias pedagógicas tradicionais. Esse aspecto pôde ser identificado em certas falas, nas quais demonstravam informaçóes verticalizadas sobre conceitos científicos que ditavam comportamentos a serem seguidos.

Por outro lado, a aproximação a uma abordagem mais dialógica, de troca de experiências do processo grupal também foi percebida (ALVES, 2005). Verificou-se valorização de oportunidades que proporcionavam horizontalidade, em oposição ao modelo de transmissão de conteúdos. Em certas falas, percebeu-se que foi dada voz às crenças, ideias e sentimentos dos membros, direcionando o grupo para uma estruturação mais psicoeducativa ou socioeducativa, dependendo das questôes de ordem psíquicas ou sociais que eram trazidas e como essas interferiam no adoecimento e na vida (AFONSO, 2010).

Mas sempre tem uma coisa diferente. Passa pro outro. O outro passa o que ta sentindo. O
que ta ocorrendo dentro da família, entendeu? (Sujeito 16, homem, 72 anos, aposentado,
casado).
Porque a gente participa desses negócios (dos grupos), aí a gente vai vendo que a gente tem
que ficar calma. Eu tava falando com uma amiga minha lá (no grupo), que eu tava muito
triste, muito doente [...] depois que eu tive uma conversa lá, com minha colega, eu me
senti melhor [...] ai quando eu to querendo dar alguma coisa, eu me lembro das palavras
que ela falou comigo. Falou tão legal, menina, que a gente sente que é gente. Tem dia que
eu não me sinto que sou gente não. (Sujeito 5, mulher, 69 anos, do lar).

Pode-se dizer que as abordagens mais tradicionais/verticalizadas, em alguns momentos, davam lugar a relações mais horizontais, sendo estas mais próximas do modelo dialógico. Açôes curativas, com enfoque na dimensão biológica do adoecimento, ainda são hegemônicas. As equipes de saúde carregam o domínio teórico organicista, centrado na racionalidade biomédica, que governa as disciplinas curriculares. Isto, aliado à aceitação cultural de que o saber popular é desqualificado, conferindo ao profissional seu status apropriado, dificulta a reconstrução de práticas voltadas para o fortalecimento da autonomia dos sujeitos (ALVES; AERTS, 2011).

Com relação aos coordenadores dos grupos de Artesanato e Atividade física funcional, percebeu-se que, embora reconhecessem os efeitos terapêuticos daqueles espaços para a saúde dos participantes, a condução das atividades se processava a partir do compartilhamento de seus conhecimentos no campo das artes e práticas corporais, respectivamente. Já as interlocuções e as problematizaçôes, a partir da leitura sobre a vida e sobre cada um, eram desenvolvidas e conduzidas pelos membros, em maneiras próprias, trazendo reflexôes sobre os modos de gerir e fazer saúde. 
Algumas maneiras inovadoras de exercer o autoconhecimento, cuidado de si e do outro, condiçôes indispensáveis para a promoção da saúde, puderam ser viabilizadas no momento em que a comunicação entre os sujeitos foi facilitada por aqueles ambientes (BRASIL, 2013). Cabe nesse âmbito, perfeitamente, a famosa frase de Freire (1987, p. 39): "Ninguém educa ninguém, ninguém se educa a si mesmo, os homens se educam entre si, mediatizados pelo mundo".

\section{Dimensão biológica}

Esta categoria surgiu a partir de relatos dos sujeitos do estudo nos quais emergiram sentidos de busca por um satisfatório funcionamento de seus corpos, com redução de fatores que elevam os riscos de danos. O foco era a prevenção das doenças ou diminuição das condiçóes de mal-estar. O paradigma da saúde, da oposição normalidade/patologia, está fortemente presente nessa perspectiva e, quase sempre, relacionado à prática médica (LUZ, 2007).

Luz (2007) desperta a atenção para a frequente abordagem de profissionais, nos atendimentos em saúde, de culpabilização dos sujeitos pelos excessos cometidos na alimentação, ingestão de álcool e hábitos que expôem a riscos de adoecimento. Nesse ponto de vista, os grupos também funcionavam, para os entrevistados, como espaços nos quais buscavam adquirir potencial para o controle de suas doenças, na lógica de obedecer a uma indicação médica para alcançar um corpo saudável.

Sou diabética, hipertensa. A doutora manda fazer caminhada, ginástica, fazer alguma coisa pra ajudar. Aí eu faço aqui porque é pertinho de casa [...]. (Sujeito 3, mulher 76 anos, casada, do lar).

[...] muitas coisas aprendi aqui. Levar minha dieta a sério se quiser ter saúde. Eu não como gordura. Náo bebo coca. Nem carne eu to comendo. (Sujeito 8, mulher 72 anos, aposentada, viúva).

Especialmente no grupo Bem-estar, foi possível observar, pelas entrevistas, que era dado amplo enfoque à dimensão biológica do processo saúde-doença e às medidas preventivistas. Os interesses que moviam as orientações sobre as práticas em saúde, tanto pelo educador quanto pelos educandos, se concentravam na dimensão instrumental para o controle das doenças. Os significados que os sujeitos atribuíam ao processo de adoecimento para adesão às medidas terapêuticas não eram valorizados, assim como as condiçôes de vida, naquele território, também ficavam excluídas das conversas (AYRES, 2007). 
Luz (2007) contribui para contextualizar essas circunstâncias ao analisar que o cenário atual se caracteriza por uma medicina tecnificada, absorvida pela economia de mercado, como fonte de oferta de serviços e bens de consumo, dirigida pelo lucro. Como resultado, sobressaem as indústrias farmacêuticas, os planos de saúde e, deste corolário, a medicalização da vida, definida como “[...] um processo de expansão progressiva do campo de intervenção da biomedicina por meio da redefinição de experiências e comportamentos humanos como se fossem problemas médicos" (TESSER, 2006, p.248).

A cultura medicalizante da biomedicina desconsidera os conceitos filosóficos embutidos na perspectiva ampla da saúde. Focaliza na luta contra entidades patológicas e seus riscos ameaçadores, prescrevendo um comportamento restritivo e rígido: não beba, não fume, faça exercício, diminua o açúcar e o sal (TESSER, 2006). Esse universo ideológico da instituição biomédica se expandiu na sociedade, principalmente em razão da mídia, provocando uma relativa obsessão por prevenção e estilo de vida saudável, chamada por Nogueira (2003) de "higiomania moderna".

No meu caso, o quê eu fiz lá em casa? Justamente o que aprendi no grupo. Do grill, pra não usar mais fritura e é bom pras filhas, agora tão aprendendo, né. Aí tem uma qualidade de vida, né. Aí quando passei a caminhar a pressão baixou [...] e eu me sinto melhor do que no dia que eu náo ando. Sinto corpo leve. (Sujeito 14, homem, 46 anos, casado).

[...] tem uma mulher aqui na comunidade, que acho que ela até já morreu. Porque tava comendo muita coisa, ai deu palpitaçáo, começou a aparecer caroço nela, ela foi pro outro lado. Eu continuo aqui. Não tenho nada, graças a Deus. (Sujeito 2, mulher 63 anos, do lar, divorciada).

Segundo Castiel, Sanz-Valero e Vasconcelos-Silva (2001, p. 111), “um bom comportamento pode resultar em ganhar o prêmio de evitar sofrimentos futuros e viver mais tempo. Um mau comportamento conduz ao sofrimento e encurtamento da vida”. Assim, segundo esses autores, é necessário muito sacrifício e autocontrole para não cometer "crime" e ser "castigado", revelando uma visão pecaminosa da ação humana atravessada por moralismos.

Por outro ângulo, considerando que a dimensão biológica também é um fator condicionante para o processo de adoecimento, prevenir e tratar as dores do corpo são igualmente determinantes para a promoção da saúde. As práticas corporais, voltadas para a aquisição de força, elasticidade e equilíbrio, e as demais atividades grupais, oferecem possibilidades de contribuir para que os sujeitos adquiram autoestima e independência em relaçáo à utilização de recursos mais tecnológicos, 
tais como medicamentos, exames, próteses. Isto só se torna possível aos indivíduos quando as medidas terapêuticas logram ser apropriadas a suas representaçóes, acessíveis, viáveis e sustentáveis na triunfante ação "desmedicalizante", promotora de autonomia (TESSER, 2006).

No entanto, açôes focadas nos fatores comportamentais de risco costumam gerar culpabilização da vítima, apagamento dos fatores estruturais e compulsão pela vigilância (CASTIEL; XAVIER; MORAES, 2016). Apesar do predomínio dessa lógica, pode-se dizer que as atividades de grupos mesclavam discursos de moderação e autocontrole com prazeres, diversão e amabilidade.

\section{Dimensão Psicoafetiva}

Aspectos psicossociais e afetivos transpareceram significativamente mais do que as outras dimensóes, tanto nas entrevistas quanto no processo de observaçáo, como motivações para frequentarem os grupos. Embora o principal objetivo das atividades corporais fosse promover a saúde física do corpo, observou-se que, naquele grupo, viabilizava-se também um espaço de convivência, no qual a socialização proporcionada era uma forte atração para os participantes.

A única coisa que ainda tá me levantando é esse grupo (de atividade física). Pra ter esse dia de levantar. Junta muita gente. A gente conversa. Vê as pessoas que a gente conhece, mas não sabe como encontrar. (Sujeito 5, mulher, 69 anos, do lar).

[...] eu acho que é isso que marca: esse afeto, esse respeito. Se uma tá para baixo, as outras falam pra não ficar assim, pergunta o que que tá acontecendo. Eu falo, assim, hoje é uma nova família, entendeu? (Sujeito 19, mulher, 27 anos, casada).

Luz (2007) ressalta que, em geral, as representações das práticas em saúde nos espaços de academia de musculação permeiam valores culturais mais ancorados no individualismo competitivo, vigentes na sociedade neoliberal, que valoriza o corpo modelado, regido pelas normas estéticas da cultura em voga, e associa saúde à força, juventude e padrôes de beleza. Em contrapartida, tal como ocorre no grupo de atividade funcional, Luz (2007) analisa que, à medida que se eleva a faixa etária e diminui o estrato social, os valores estáo mais embasados na harmonia e equilíbrio corpo e mente. Segundo a autora, em geral, esse público busca atividades mais suaves, que incluem dança, alongamento, hidroginástica. Nesse âmbito, a saúde, para essas pessoas, se encontra predominantemente permeada de emoçóes e sentimentos, sobressaindo uma dimensão subjetiva. 
Além do grupo de Atividade física, os grupos de Artesanato e Bem-estar também favoreciam espaços de sociabilidade, em que se formaram redes sociais e grupos de amizade, resultando em relaçóes de solidariedade, fraternidade, apoio mútuo, em contraposição aos valores dominantes da competição e individualismo (LUZ, 2007). Tornava-se um campo relacional em que as pessoas ora cuidavam, ora eram cuidadas.

Havia uma tendência de ressignificar atividades designadas como lúdicas, tais como jogos, passeios, excursões e comemoraçôes em açôes promotoras da saúde. O grupo de Atividade física funcional promovia diversas excursōes, por exemplo, a museus, trilhas e visitas a pontos turísticos. Neste grupo, e no de artesanato, também se organizavam comemoraçóes de datas especiais e de aniversário. Esses encontros proporcionavam relaçóes de afeto e amorosidade; prazer em conhecer lugares novos, com a "comilança" das confraternizaçóes, com brincadeiras e sorrisos; sentimentos positivos favoráveis ao bem viver daquelas pessoas, tornando-se mecanismos de superação de diferentes situaçôes de sofrimento em suas vidas.

Eu fui lá na Urca (o passeio com o grupo de atividade física). Eu fiquei meia assim, atordoada (estava em tratamento para síndrome do pânico), mas depois foi indo..., ali, na brincadeira, a gente foi caminhando, conversando, eu fui respirando, aí, o mar, aquela coisa linda, que só Deus pode nos presentear, aí foi aliviando. (Sujeito 9, mulher, 46 anos, casada, do lar).

Campos e Furlan (2010) contribuem para a compreensão dessas questôes ao dizer que a prática grupal possibilita a agregação de pessoas que se reconhecem afins, por apresentarem pensamentos, histórias de vida, valores e hábitos semelhantes, propiciando o sentimento de grupalidade, de pertencimento, fortalecendo os vínculos de suporte para além dos grupos. O autor chama essa conexão entre os membros de "caixa de ressonância", fazendo uma analogia a um violão, em que aquilo que é dito ou expressado, ressoa sobre o outro, isto é, toca e afeta.

Uma considerável observação foi a relação de acolhimento amoroso que havia entre os coordenadores dos grupos de Artesanato e Atividade física e seus membros. Segundo Casanova et al. (2012), esse vínculo entre facilitador e integrantes é primordial para que quaisquer intervençôes, clínicas ou psicoterapêuticas, dentro das dinâmicas grupais, tenham efetividade. De fato, aqueles laços eram fundamentais para amplificar as motivaçôes para a participação, conforme verificado nos relatos:

[...] porque as pessoas estão para baixo, tô com isso... Então, vamos para o grupo fazer exercício, conversar. A professora é legal. Ela é nossa amiga também, que acaba dando conselho para gente. (Sujeito 19, mulher, 27 anos, casada). 
A agente comunitária de saúde (ACS), que coordenava o grupo de Artesanato, morava na mesma comunidade que quase todos os participantes; conhecia bem suas famílias, redes sociais, rotinas e parte das situaçôes de adversidade as quais vivenciavam. Em um dos dias presente nessa atividade, foi possível observar que, enquanto os componentes executavam as orientações para a construção dos trabalhos manuais, conversavam sobre filhos, netos que davam trabalho, coisas da vida, que lhes agradavam ou não, a ACS interagia com todos, demonstrando proximidade e vínculo. Valla (1999) aponta que os agentes de saúde podem configurar uma proposta de revisão das açôes em saúde por meio de novas criaçôes e soluçôes nos modos de oferecer cuidado. O fosso cultural existente entre os profissionais graduados e os grupos populares nas suas formas de linguagem e concepçóes de mundo torna o papel do agente comunitário fundamental, como elo entre as duas realidades, e possível facilitador dessas relaçóes. Por pertencerem àquele território, conhecem as necessidades de saúde e dificuldades para alcançá-las, sendo capazes de oferecer soluçôes que se contrapóem aos limites biomédicos. $\mathrm{O}$ autor ainda ressalta que a valorização da cultura local e da religiosidade possibilita formas de assistência relevantes por meio do apoio social. Isto pode ser corroborado pelo seguinte relato:[...] eu fico muito tempo sozinha em casa, minha filha sai de manhã, neta também. Só chegam de noite [...] todo mundo me dá atenção aqui [...] quando chego de manhã aqui, as meninas do grupo, essas agentes [ACSs do grupo de Atividade funcional e Artesanato], elas fazem uma oração ali atrás [...] elas me convidaram pra participar. (Sujeito 10, mulher, 77 anos, aposentada, viúva).

\section{Considerações finais}

A Política Nacional de Promoção da Saúde tem como um de seus valores e princípios o reconhecimento da subjetividade no processo saúde cuidado (BRASIL, 2015), o que foi observado nos resultados obtidos neste artigo. Finitude, solidão, tristeza, desesperança, limitação, saudade, amorosidade, amizade e parceria constituíram uma gama de emoçóes e sentimentos que emergiram dos relatos, como parte do cotidiano da vida dos sujeitos, motivando também a busca por participação nos grupos ofertados pela Clínica da Família pesquisada.

Ayres (2001) propóe que se valorizem as intersubjetividades na perspectiva da ipseidade, ou seja, na identidade construída a partir da experiência com o outro, no intuito de se reconhecer enquanto sujeito, defendendo, assim, o caráter relacional 
como reconstrutivo das identidades subjetivas em oposição à ideia de permanência, de mesmidade do pensamento sanitário. Para o autor, as relações são entendidas como potenciais transformadores das identidades, no sentido de alcançar sucesso prático terapêutico em projetos pessoais de bem-viver. Sendo assim, as atividades de grupos nos pareceram proporcionar e ampliar espaços de interrelaçóes, trocas e construção de saberes.

Adotando-se a definição de saúde de Canguilhem (2009), na qual se considera a margem de tolerância para as infidelidades, restaura-se a noção de que todos os seres humanos inevitavelmente possuem, em suas vidas, fatores estressantes (ou desafios) que podem ser de ordem física, afetiva e/ou psicológica. Contudo, foi possível observar alguns mecanismos próprios desenvolvidos para lidar ou superar os eventos negativos que os sujeitos relataram enfrentar. Pode-se pensar, metaforicamente, sobre o processo saúde-adoecer, e suas construções subjetivas, como uma espécie de gangorra, que se eleva ou declina, sob interferência dos fatores de proteçáo/ superação e dos fatores estressantes. Observou-se que a elevaçáo da gangorra, para o lado da saúde, ocorreu mais quando as pessoas se ocuparam umas com as outras, independentemente do tipo de exercício, atividade ou local, fazendo supor que um olhar solidário e coletivo evoca a saúde.

A inclusão de profissionais que não eram de nível superior, bem como os próprios usuários, nos processos de cuidado, naqueles espaços de diálogo, se tornou um poderoso recurso para incremento da corresponsabilização e autonomia. Sinalizou um potencial de ruptura com práticas convencionais e hegemônicas, orientadas para o controle técnico das doenças e medicalizantes. Ao se refletir sobre as práticas que utilizam lógicas integrativas, de convivência e acolhimento, como as atividades de grupo estudadas, percebe-se um passo importante, desse tipo de abordagem, em direção aos princípios de solidariedade, mutualidade e cordialidade; preceitos estes que, atualmente, parecem estar sendo negados pelos valores individualistas, consumistas e competitivos do capitalismo neoliberal.

Os grupos de educação em saúde na APS, apesar de possuírem enorme potencial para o enfrentamento de açóes contra-hegemônicas, ainda podem ser considerados pouco aproveitados. Embora a PNAB (2017) atribua a todos os profissionais a abordagem de grupos como uma ferramenta terapêutica, de acordo com Campos e Furlan (2010), faltam aos profissionais instrumentos e conhecimento sobre dinâmicas grupais. De fato, nenhum dos coordenadores dos três grupos passou por qualquer tipo 
de qualificação em Educação em Saúde. Entendemos que essa situação é decorrente de uma formação profissional baseada em uma racionalidade fragmentadora de práticas e promotora de encontros individuais em detrimento de encontros coletivos.

Apesar das dificuldades de formação para coordenar um grupo, que efetivamente possa alcançar suas potencialidades; as vivências nesse tipo de atividade, que parecem ser primordiais, possibilitam exercitar a escuta, mediaçóes dos diálogos, lidar com frustações e permitir que as pessoas mais introvertidas se expressem (CAMPOS; FURLAN, 2010). Certamente, investir nos profissionais de saúde com vistas a estimular o trabalho com grupos, especialmente na APS, construiria solidez e reafirmação dos princípios do SUS.

Se o trabalho com grupos desafia o estabelecimento do modelo tecnoassistencial, desafia também a produção de condutas medicalizantes, voltadas exclusivamente para as doenças, que costumam impregnar as linhas de cuidado em saúde de uma maneira geral. Esse é um enfrentamento que o trabalho com grupos certamente terá que lidar, seja na universidade e cursos técnicos, caso olhemos para a formação profissional; seja nos serviços, caso olhemos para o mundo do trabalho.

Retomando a metáfora da gangorra sobre o processo saúde-doença, é essencial um olhar voltado para a integralidade e a complexidade dos sujeitos, nos quais as dimensôes biológica, afetiva, psicológica, social e espiritual exigem postura dialógica, interprofissional e interdisciplinar. Como apreendido neste estudo, o lado da saúde tende a se erguer, na medida em que, para além do olhar integral sobre indivíduos/ comunidade e das açôes coletivas, as maneiras de produzir saúde sejam integradoras, cooperativas e solidárias, especialmente quando os sujeitos vivem num território em que as condições já contribuem para o declínio da saúde. ${ }^{1}$

\section{Referências}

AFONSO, M. L et al. Oficinas em dinâmica de grupo na área da saúde. 2 ed. São Paulo: Casa do Psicólogo, 2010.

ALVES, G. G.; AERTS, D. As práticas educativas em saúde e a Estratégia Saúde da Família. Ciência \& Saúde Coletiva. Rio de Janeiro, v. 16, n. 1, p. 319-325, 2011.

ALVES, V. S. Um modelo de educação em saúde para o Programa Saúde da Família: pela integralidade da atençâo e reorientação do modelo assistencial. Interface. Botucatu, v. 9, n. 16, p. 39-52, 2005. 
AYRES, J. R. C. M. Sujeito, intersubjetividade e práticas de saúde. Ciência \& Saúde Coletiva. Rio de Janeiro, v. 6, n. 1, p. 63-72, 2001.

. Uma concepção hermenêutica de saúde. Physis: Revista de Saúde Coletiva. Rio de Janeiro, v. 17, n. 1, p. 43-62, 2007.

BARDIN, L. Análise de conteúdo. Lisboa: Edições 70, 2008.

BRASIL. Ministério da Saúde. Conselho Nacional de Saúde. Resolução no 466, de 12 de dezembro de 2012. Disponível em: <http://conselho.saude.gov.br/resolucoes/2012/Reso466. pdf>. Acesso em: 12 jun. 2017.

- Ministério da Saúde. Departamento de Atenção Básica. Política Nacional de Atenção Básica. Portaria no 2.435, de 21 de setembro de 2017. Diário Oficial da União. Disponível em: $\quad<$ http://pesquisa.in.gov.br/imprensa/jsp/visualiza/index.jsp?jornal=1\&pagina=68\&da $\mathrm{ta}=22 / 09 / 2017>$ Acesso em: 5 maio 2018.

- Ministério da Saúde. Secretaria de Atenção à Saúde. Núcleo Técnico da Política Nacional de Humanização. Humaniza SUS: documento base para gestores e trabalhadores do SUS. 4a ed. Brasília: Ministério da Saúde, 2010.

- Ministério da Saúde. Secretaria de Gestão Estratégica e Participativa Departamento de Apoio a Gestão Participativa. Política Nacional de Educação Popular em Saúde PNEP-SUS. Brasília: Ministério da Saúde, 2013.

- Ministério da Saúde. Secretaria de Vigilância em Saúde. Secretaria de Atenção à Saúde. Política Nacional de Promoção da Saúde (PNPS). Revisão da Portaria MS/GM nº 687, de 30 de março de 2006. Brasília: Ministério da Saúde, 2015.

BUSS, P. M. Uma introdução ao conceito de promoção da saúde. In: CZERESNIA, D.; FREITAS, C. M. (Orgs.). Promoção da saúde: conceitos, reflexôes, tendências. Rio de Janeiro: Editora Fiocruz, p. 15-38, 2003.

CAMPOS, G. W. S; FURLAN, P. G. Os Grupos na Atenção Básica In: BRASIL. Ministério da Saúde. Secretaria de Atenção à Saúde. Política Nacional de Humanização. Atenção Básica/ Ministério da Saúde, Secretaria de Atenção à Saúde, Política Nacional de Humanização. Brasília: Ministério da Saúde, 2010.

CAMARGO, JR., K. R. Das necessidades de saúde à demanda socialmente constituída. In: PINHEIRO, R.; MATTOS, R.A. (Orgs.). Construção Social da demanda: direito à saúde, trabalho em equipe, participação e espaços públicos. Rio de Janeiro: CEPESC/UERJ: Abrasco, 2005.

CANGUILHEM, G. O normal e o patológico. 6º ed. Rio de Janeiro: Forense Universitária; 2009.

CASANOVA, F.; OSORIO, L. C.; DIAS, L. Abordagem comunitária: grupos na atenção primária à saúde. In: GUSTAVO, G.; CERATTI, J. M. (Orgs.). Tratado de medicina de família e comunidade. Princípios, formação e prática. Porto Alegre: Artmed, 2012. 
CASTIEL, L. D.; SANZ-VALERO, J.; VASCONCELOS-SILVA, P. R. Das Loucuras da Razão ao Sexo dos Anjos: biopolítica, hiperprevenção, produtividade científica. Rio de Janeiro: Editora Fiocruz, 2011.

CASTIEL, L. D.; XAVIER, C.; MORAES, D. R. À procura de um mundo melhor: apontamentos sobre o cinismo em saúde. Rio de Janeiro: Editora Fiocruz, 2016.

FREIRE, P. Pedagogia do oprimido. 17 ed. Rio de Janeiro: Editora Paz e Terra, 1987.

FOUCAULT, M. O nascimento da clínica. 2a . Ed. Rio de Janeiro: Forense-Universitária, 1980.

LOPES, R.; TOCANTINS, F. R. Promoção da saúde e a educação crítica. Interface.Botucatu, v. 16, n. 40, p. 235-248, 2012.

LUZ, M. T. Novos saberes e práticas em saúde coletiva: estudos sobre racionalidades médicas e atividades corporais. $3^{\text {a }}$ ed. São Paulo: Hucitec, 2007.

GIL, A. C. Como elaborar projetos de pesquisa. 4º ed. São Paulo: Atlas, 2008.

MALTA, D. C. et al. Política Nacional de Promoção da Saúde (PNPS): capítulos de uma caminhada ainda em construçáo. Ciência \& Saúde Coletiva. Rio de Janeiro, v. 21, n. 6, p. 16831694, 2016.

MARCONI, M. A.; LAKATOS, E. M. Fundamentos da metodologia cientifica. 5a ed. São Paulo: Atlas, 2003.

MATTOS, R. A.; BAPTISTA, T. W. F (Orgs.). Caminhos para análise das politicas de saúde. Porto Alegre: Rede UNIDA, 2015.

MINAYO, M. C. S. O desafio do conhecimento: pesquisa qualitativa em saúde. 14.ed. São Paulo: Hucitec, 2014.

NASCIMENTO, M. C.; ROMANO, V. F.; MOSEGUI, G. B. G. Medicalização da vida. In: NASCIMENTO, M. C.; GUEDES, C. R. (Orgs.). Saúde, sociedade e cultura: ciências sociais e humanas para graduação em saúde. São Paulo: Hucitec, 2017.

NOGUEIRA, R. P. A saúde pelo avesso. Natal: Seminare, 2003.

SCHWANDT, T. Três posturas epistemológicas para a investigação qualitativa. In: DENZIN NORMAN K; LINCOLN S (Orgs.). O Planejamento da Pesquisa Qualitativa: teorias e abordagens. Porto Alegre: Artmed, p. 193-217, 2006.

SILVA, P. F. A.; BAPTISTA, T. W. F. A Política Nacional de Promoção da Saúde: texto e contexto de uma política. Saúde em Debate Rio de Janeiro,39, esp., p. 91-104, 2015.

. Os sentidos e disputas na construção da Política Nacional de Promoção da Saúde. Physis: Revista de Saúde Coletiva. Rio de Janeiro, v.24, n. 2, p. 441-465, 2014. 
TESSER, C. D. Medicalização social (II): limites biomédicos e propostas para a clínica na atenção básica. Interface. Botucatu, v. 10, n.20, p. 347-62, 2006.

VALLA, V. V. Educação popular, saúde comunitária e apoio social numa conjuntura de globalizaçấo. Cadernos de Saúde Pública. Rio de Janeiro, v.15, n.2, p. 7-14, 1999.

\section{Nota}

${ }^{1}$ L. S. Rego e M. R. Baião trabalharam em todas as etapas, desde a concepção do estudo até a revisão final do artigo. V. F. Romano e G. de O. Figueiredo participaram da redação, revisão crítica do artigo e aprovação da versão final. 


\section{Abstract}

\section{Group activities in the perspective of individuals in a Family Health Unit}

This study aims to analyze the meanings that individuals give to collective activities performed at a Family Health Unit in Rio de Janeiro. Data were collected through semi-structured interviews with participants and systematic observation of the three different groups. Information was processed by adapting the analysis of thematic content with the support of the interpretative perspective. Were identified three analytical categories in the interviewees' speech, namely: "Biological dimension", "Psycho-affective dimension" and "Educational dimension". Interpersonal exchanges were processed mainly by reflection from the subjects' life experience, which allowed for a different approach to the care needs of users based on the reception provided by the collective and the bonds built. The results demonstrate that the approaches of group can transform biomedical hegemonic model of health practices.

Keywords: Primary Health Care; Health Promotion; Health Education, Family and Community Medicine. 